\title{
A CONTRIBUTION TO THE STUDY OF TUMORS FROM THE PRIMITIVE NOTOCHORD
}

\author{
N. D. C. LEWIS, M.D. \\ WASHINGTON, D. C.
}

The notochord or chorda dorsalis of the amphioxus, in which it is the only axial skeleton, and in fishes and amphibians, in which it is still persistent in the axial skeleton, is of entodermal origin, while in the higher vertebrates the notochordal process and the mesoderm are apparently derived from the ectoderm. In developing embryos of the higher vertebrates, it becomes enclosed in the centers of the vertebrae and in the modified vertebrae forming the base of the cranium, in which sites it eventually and usually early in the mammals, degenerates, with the exception of residuals known as pulpy masses or nuclei pulposi located in the intervertebral discs.

The normal embryonic residual notochord tissue is composed of rather large, round or slightly oval, acidophilic epithelial cells which develop vacuoles containing mucein. In later stages, the cell wall disappears, thus freeing the cytoplasm which fuses with that of other adjacent cells, forming a syncytial structure which is not unlike that of fetal connective tissue. The adult notochord tissue is characterized by large cells containing vacuoles, eccentric, angular nuclei, and is bound together by a syncytial type of cytoplasm.

Abnormal growths of notochord tissue have most commonly been found at the spheno-occipital synchondrosis at the upper end of the notochord behind the pituitary body, and in the sacrococcygeal region, the lower end of the cord, although at least one has been described which occurred at the level of the upper cervical vertebrae. ${ }^{1}$ Many of the so-called chordomas are small benign masses of this tissue which has during early development been forced out of the bone, being probably analogous to other better known types of tissue displacement.

Virchow ${ }^{2}$ termed these growths from the synchondrosis "ecchondrosis physalifora" because of the vacuolated, degenerated cell surrounded by a bluish hyalin-like substance appearing somewhat like cartilage, and Mueller ${ }^{3}$ was apparently the first to be of the opinion that these small masses originate from rests of notochordal cells. These small chordomas, when growing in the cranium, have been

1. Klebs: Allegemeine Pathologie, Pt. 2, 693.

2. Virchow: Entwickelung des Schädelgrundes in den krankhaften Geschwïlste.

3. Mueller, H.: Ueber das Vorkommen von Resten der Chorda dorsalis beim Menschen nach der Geburt und über ihr Verhältnis zu den Gallert geschwülsten am Klivus, Ztschr. f. rat. Med. 2:202, 1858. 
known to assume dimensions great enough to produce symptoms of intracranial pressure, ${ }^{*}$ but usually, as shown by Ribbert's " investigations on these tumors of the region of the clivus, the growths are small and soft, hence do not produce clinical manifestations, are connected by the slender pedicle with similar tissue imbedded in the bone, perforate the dura, and often are attached to the basilar artery. He stated that these small nodules, to which he gave the name chordoma, were found in 2 per cent. of all necropsies.

I have recently removed at necropsy one of these soft pale gelatinous, pea-sized tumors from the clivus blumenbachii. This small growth was attached by a pedicle to a similar structure imbedded in the bone and had perforated the dura. Microscopic examination revealed a pale, basic staining cartilaginous appearing matrix in which there were a few large vacuolated cells with marginal nuclei. (Fig. 6-C).

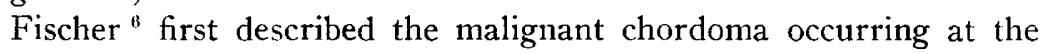
base of the skull, and malignant, invasive chordomas of the sacrococcygeal region have been described by Mazzia, ${ }^{7}$ Albert ${ }^{8}$ and others.

Because of the peculiar vacuolization of cells, the arrangement and staining properties of the matrix and invasive mode of extension, the differentiation of chordoma, myxochondroma and colloid carcinoma is often difficult, and doubtless many errors have arisen in this connection, particularly when the growth has occurred in the sacral region. The few differentiating features will be discussed at the end of this paper.

With the exception of Albert's case, I am not aware of any written reports of these cases in this country, and as instances of malignant chordoma are rare, their pathologic characteristics are not well known, and as four are now available for analysis it seems desirable to publish such an account.

Case 1 came to necropsy in our laboratory at Saint Elizabeth's Hospital. Case 2 was seen by Lieutenant Commander John Harper, U. S. Naval Medical School. Cases 3 and 4 were brought to my attention by Dr. Joseph C. Bloodgood of Johns Hopkins University, who kindly gave permission and material from the records for their publication.

4. Grahl: Eine Ecchondrosis Physalifora Spheno-Occipitalis Ungewöhnlichen Umfanges, Dissertation, Göttingen, 1903.

5. Ribbert: Zentralbl. f. path. Anat., p. 149, 1894, Geschwülstlehre, p. 149, 1904.

6. Fischer: Ueber ein malignes chordom der Schädelrüchgratshöhle, Beitr. z. path. Anat. u. z. allg. Path., Jena 40: 1907.

7. Mazzia: Chordom der Sakralgegend, Zentralbl. f. allg. Path. u. path. Anat. $21: 769,1910$.

8. Albert, H.: Chordom, with the Report of a Malignant Case from the Sacrococcygeal Region, Surg., Gynec. \& Obst. 21:776, 1915. 


\section{REPORT OF CASES}

CASE 1 (1921).-Male, white, aged 54, born in Ireland, soldier, stated that his habits were always good. He never drank to excess, worked regularly and had always been in good health until the age of 23 when he had an acute mental upset which led to his arrest and commitment to the Government Hospital for the Insane, where he remained until his death.

Family history not available.

Physical Examinations at the time of admission and during the following ten years showed no abnormalities. Mentally he was of the paranoid constitution, admitting occasional auditory hallucinations, frequently becoming restless and excited, walking up and down the ward talking angrily to himself in profane and vulgar language.

Present Illness.--Six years ago the patient was described as being neat in dress and habits, sleeping well, and apparently in good physical condition with the exception of "lumbago" pains and external hemorrhoids. A Wassermann reaction at this time was weakly positive, and probably without significance. During the next year there was mentioned that the patient was frequently violently angry at some of his associates and was engaged in several ward fights (possibility of coccygeal injury). A year before death, he had a parole, did fairly efficient work in the dining room, but had a few rather insignificant delusions. His physical health was recorded as satisfactory.

Four months before death it is stated that he was suffering from diarrhea and tenderness of the abdomen. A month later, he complained of gastrointestinal pain, nausea, diarrhea and headache. A large nodular mass surrounding the rectum and bladder, the functions of which were intact, was palpated in the pelvis. There was sufficient abdominal and pelvic pressure to produce severe alterations in the circulation of the thighs and scrotum, which were edematous and cyanotic. Palpation of the body surface showed a boardlike rigidity of the inner portion of the left thigh, and of the abdomen as high as the umbilicus. There was considerable induration about the testicles.

Diagnosis.-A diagnosis of inoperable pelvic malignancy was made.

Clinical Course.-The patient gradually became weaker and more emaciated until death supervened, a little over three months after acute symptoms were noticed.

\section{POSTMORTEM FINDINGS}

External Examination (twenty hours after death): The subject was a middle aged man with a slender skeleton and a large type of skull; the body was considerably emaciated, but showed residuals of former powerful muscles. There was a diffuse bluish-yellow cast to the skin. The entire abdomen below the umbilicus was extremely firm and rigid, as was also the area over the adductor group of muscles of the left thigh, as outlined in Figure 1 . The boardlike resistance of this area gave one the impression of an ossifying myositis.

The penis was edematous and the testicles were drawn tightly against and attached to the os pubis to the extent of complete immobility. The perineum was also resistant to pressure.

The skin covering these areas was unbroken and evinced no pathologic changes.

Internal Examination: On section of the abdomen, the parietal peritoneum from the level of the umbilicus downward into the bladder region was thick, white, glistening, slightly roughened, extremely fibrous, and had the consistence of cartilaginous structure. Near the pubic bone, the peritoneum averaged from 8 to $10 \mathrm{~mm}$. in thickness, gradually thinning out toward the umbilicus. The landmarks of the pelvic and dorsal peritoneum were completely obliterated by solid continuous sheets of tumor invasion.

Tumor.-The principal mass was now located and found to fill the entire pelvis proper, enclosing the rectum, bladder and other pelvic viscera in a firm encasement. Its broad attachment to the entire sacral curvature from near 


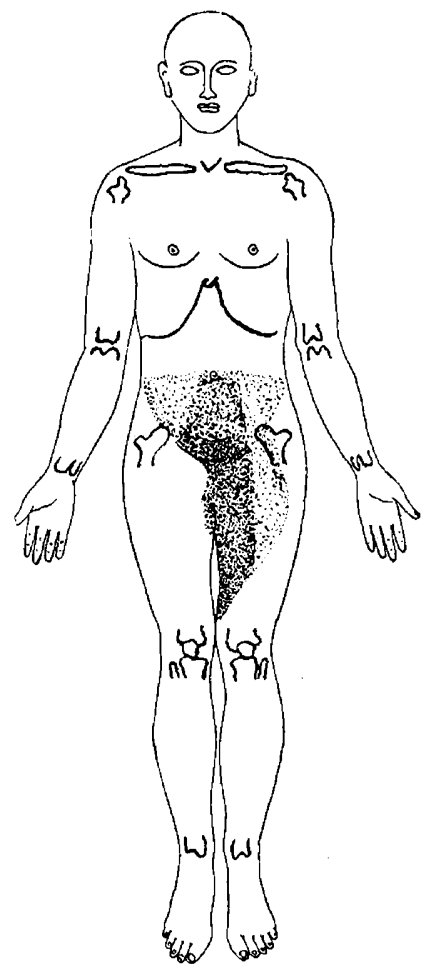

Fig. 1.-The shaded area outlines the extent of surface rigidity.

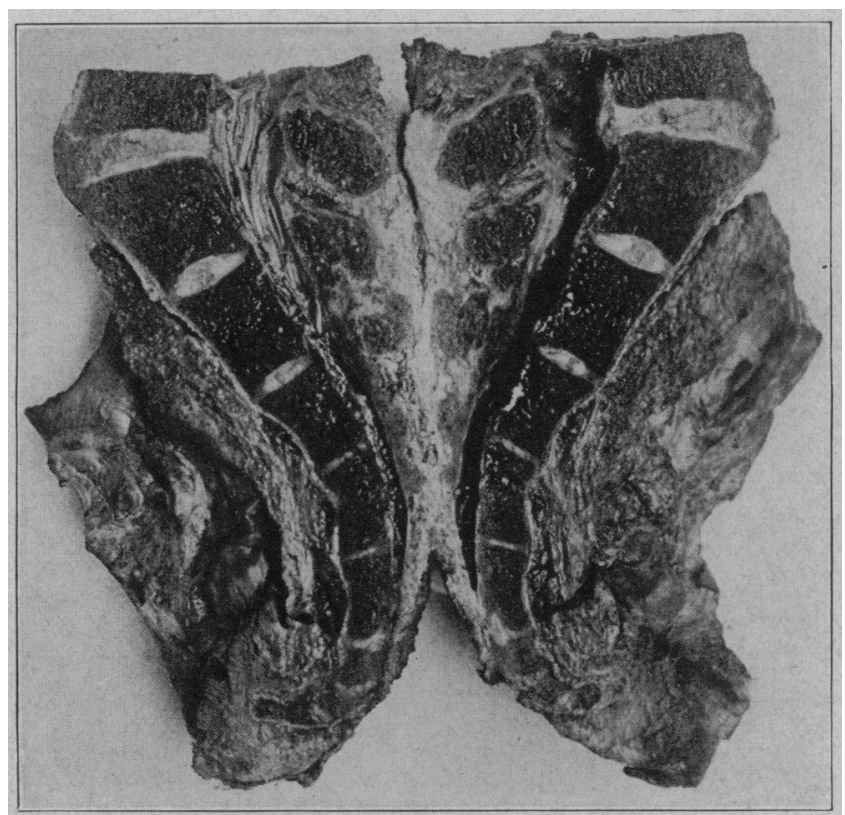

Fig. 2.-Section of sacrum and coccyx showing the broad attachment of the principal tumor mass to the curvature. 
the promontorium to and surrounding the tip of the coccyx is illustrated in Figure 2. Gross sections of the main mass revealed a whitish, firm, inelastic tissue in which small orange-colored fat accumulations were entrapped.

A large fossa was produced in the tumor by the laborious removal of the bladder and rectum. The bladder was sacculated in a long conelike extension at the apex, compensatory to the extreme rigidity and immobility of the remainder of its walls. The ureter was intact and the mucosa of the entire structure exhibited pressure changes and punctate hemorrhages, but no actual erosions.

Prostate-The prostate gland was under considerable pressure from the surrounding growth which had completely filled the capsule, but had not entered the glandular substance (Fig. 3, B).

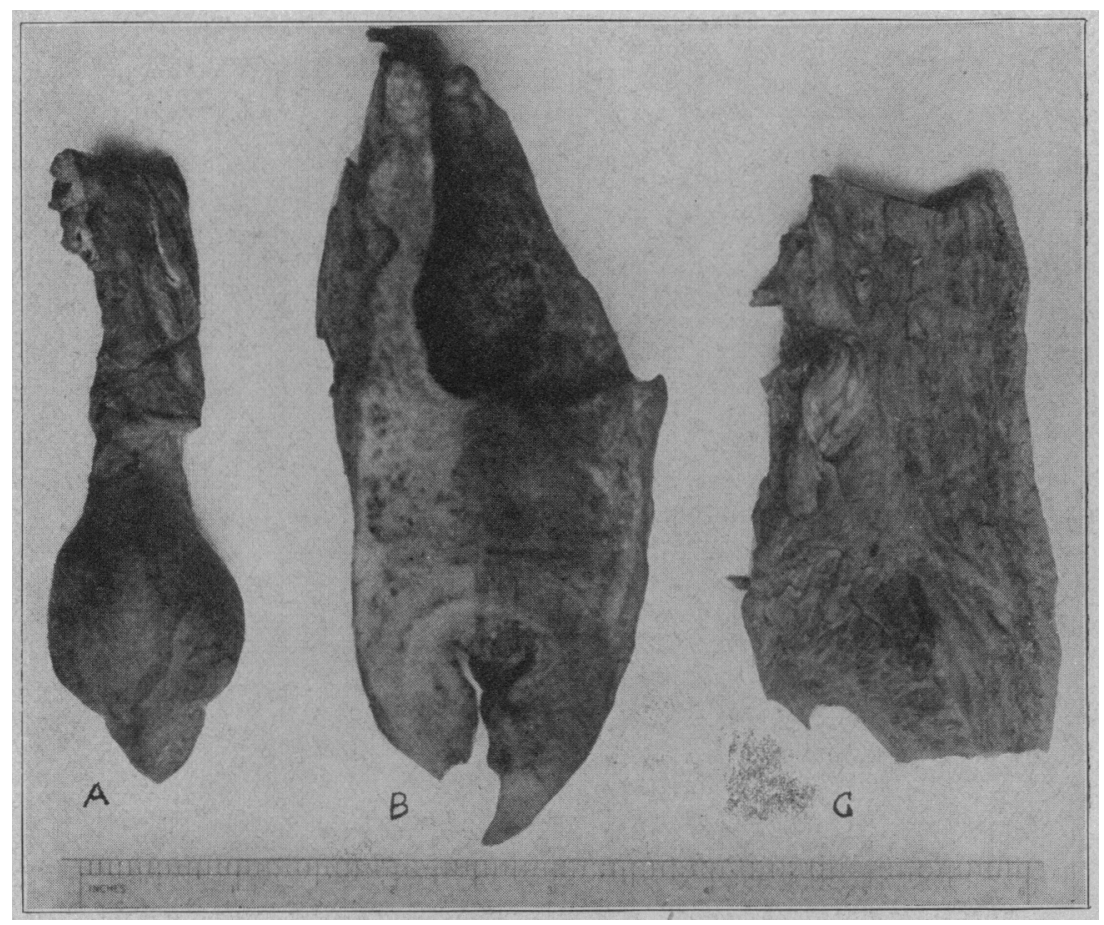

Fig. 3.-A, testicle and cord surrounded by solid tumor growth; B, section of infiltrated bladder and rectal walls with prostate between; $C$, section of the skin and thickened subcutaneous tissues of the thigh.

Rectum and Sigmoid.-The walls of the rectum and sigmoid were completely infiltrated with foreign growth as far as the mucosa, which showed hypertrophic and advanced hemorrhagic changes; the lumen of the gut was open throughout but distorted. The entire gut, including the sigmoid and lower portion of the descending colon was almost inflexible and reminded one of stiff garden hose. The mesenteries of the colon and small intestines presented a mild but distinct increase in texture, and in patches were tightly attached to the abdominal and pelvic fascias, allowing very little mobility to the intestinal tubes. The growth extended through the mesenteries in a thin sheet with no nodules and without infiltrating the lymph glands, which were normal in size and color. The infiltration of the tumor extended upward as high as the trans- 
verse colon but had not affected the walls or attachments of the stomach. The walls of the small intestines were not grossly infiltrated, and the mucous membranes were normal in appearance.

Liver.-The undersurface of the diaphragm, the capsule and ligaments of the liver were not affected. The liver exhibited a diffuse edematous, toxic, congested appearance, with a moderate central lobular degeneration. The gallbladder was small but contained normal appearing bile.

Splecn.-The spleen was imbedded in a thick, firm, gray capsule of foreign growth, which was not nodular but slightly roughened and enclosed the organ like a case. In general, it stripped easily from the surface, but firmly adhered to the capsule in patches. The substance of the spleen presented productive interstitial changes, but no gross invasion of the tumor.

Pancreas.-The pancreas was surrounded by sheets of tumor growth, which had followed the connective tissue and vessels into the gland, ramifying profusely between the lobules which were affected only by pressure changes.

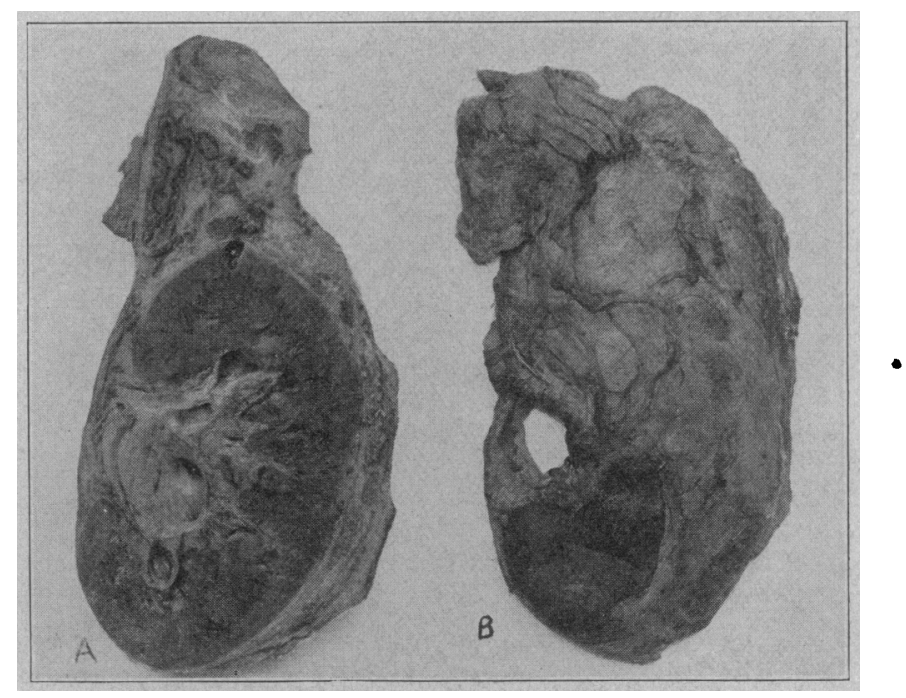

Fig. 4.-A, section of the kidney showing thickened capsule, infiltration of pelvis, and imbedding of adrenal in chordoma extensions; B, kidney capsule diffusely infiltrated with chordoma.

$K:$ nneys.-Both kidneys were encased by neoplastic growth which had fused with and stripped along with the capsule, leaving the surface of the organs corrugated from the prolonged effects of diffuse productive nephritis. Sections exhibited congestion and acute changes through the cortex. The tumor had extended along the ureters and vessels in the pelvis of the organ with extensions through the peripelvic fat and about the papillae (Fig. 4). The ureters were surrounded by the tumor, and the walls were infiltrated, but the lumina were patent.

Suprarenals.-The suprarenal glands were deeply imbedded in the tumor mass (Fig. 4), and showed exhaustion of the medulla, and many minute cortical hypertrophies.

Pelvic Fascia.-Extending from the sacral area through the pelvic fascias, which in places were half an inch in thickness, the tumor spread over the left Poupart's ligament and down the subcutaneous tissues of the inner portion of the left thigh nearly as far as the knee, crowding the adductor group of 
muscles beneath it, but apparently not infiltrating them. In places, these subcutaneous tissues were $1 \frac{1}{2}$ inches in thickness, grayish in color, and of cartilaginous texture mixed with fat (Fig. $3 \mathrm{C}$ ). The subcutaneous tissues of the outer portion of this thigh and the fascia lata were normal in appearance. The tumor had not extended below Poupart's ligament of the right side, but had grown centrally into the tunics of the testicles, completely surrounding but not infiltrating the glandular substance, although radiations could be traced into the mediastinum testis. There was apparently, in addition to the actual tumor, a tremendous fibrous tissue response, so that the structures were bound tightly to the pubic bone. The spermatic cords with their structures and extensions were heavily infiltrated, firm, rounded and had attained the diameter of one-half inch (Fig. $3 \mathrm{~A}$ ).

Lungs.-Detailed examination of the thoracic viscera revealed neither evidence of tumor extension above the diaphragm nor gross metastases.

The lungs were both free in the pleural cavities, with the exception of a few well organized adhesions at the left apex, and the upper lobes were collapsed. Section revealed normal upper lobes, while the lower lobes of both organs showed a moderate congestion and edema without consolidations. The mucous membranes of the trachea and bronchi appeared somewhat anemic.

Thyroid.-The thyroid revealed a reduction in the amount of colloid and advanced interstitial changes.

Heart.-The heart was in normal position, and the pericardium was not remarkable. The muscles were rather pale in color and the cardiac veins considerably distended. In general, the organ was normal considering the age with valves in good condition and only a slight interstitial myocarditis. Aorta was normal with the exception of a mild fibro-fatty plaque production.

Skull.-The skull was thin throughout but the parietal bones were extremely so. The dura mater was slightly adherent to the calvarium and thickened to tne extent that the brain convolutions were not easily visible through it. The cerebrospinal fluid was apparently normal.

Brain.-The brain weighed $1,200 \mathrm{gm}$. and was remarkably anemic, the larger veins being empty and the smaller capillaries barely visible. The brain substance was universally edematous, and the arteries of the base showed a few discrete arteriosclerotic nodules, but otherwise there were no gross abnormalities.

Pituitary.-The pituitary gland with the sella turcica was not unusual.

\section{MICROSCOPIC EXAMINATION}

Sections from Sacral Tumor: The connective tissue response through these sections was remarkable and large bands of this structure were filled with the characteristic cells of malignant notochordal tissue. In many places there were localized groups of large vacuolated cells, bearing eccentric nuclei of various sizes, and lying in a pale, finely granular matrix, while in other fields these cells were thinly scattered through the fibrous tissue.

In some areas there were many variations in the cell structures and type of arrangement. The classification I offer is descriptive of the types frequently encountered (Fig. 5).

1. Cells with thin rim of finely granular protoplasm, a single large central vacuole which has often ruptured the enclosing protoplasm, and a marginal nucleus which varies in size, staining properties, and is often multiple (b).

2. Cells with a heavily stained, irregular nucleus only slightly eccentric and with relatively more protoplasm bearing several large sized vacuoles (a).

3. Cuboidal, polyhedral or columnar cells with central irregular nucleus and protoplasm with a few small vacuoles (c).

4. Large cuboidal or columnar cells with a narrow, marginal, irregular, heavily stained nucleus, and relatively large amount of protoplasm containing a few small vacuoles (d). 
5. Slightly irregular cuboidal, polyhedral or rounded cells bearing a relatively large granular nucleus and without vacuoles in the protoplasm (c).

6. Irregular and compound cells with peculiar arrangements of the nucleus and protoplasm-formed probably by fusion of cells after partial discharge of mucein or by cell division under pressure (f).

Sections of Skin and Subcutaneous Tissue.-The skin layers, the hair follicles, sebaceous and suderiferous glands were apparently normal; however, about some of the lower sweat glands, chordoma cells were seen proliferating, often lying up tightly against the basement membrane. The fibroblastic and fatty elements of the subcutaneous tissues were enormously increased and diffusely infiltrated by the foreign cells, bunches of which were accumulated

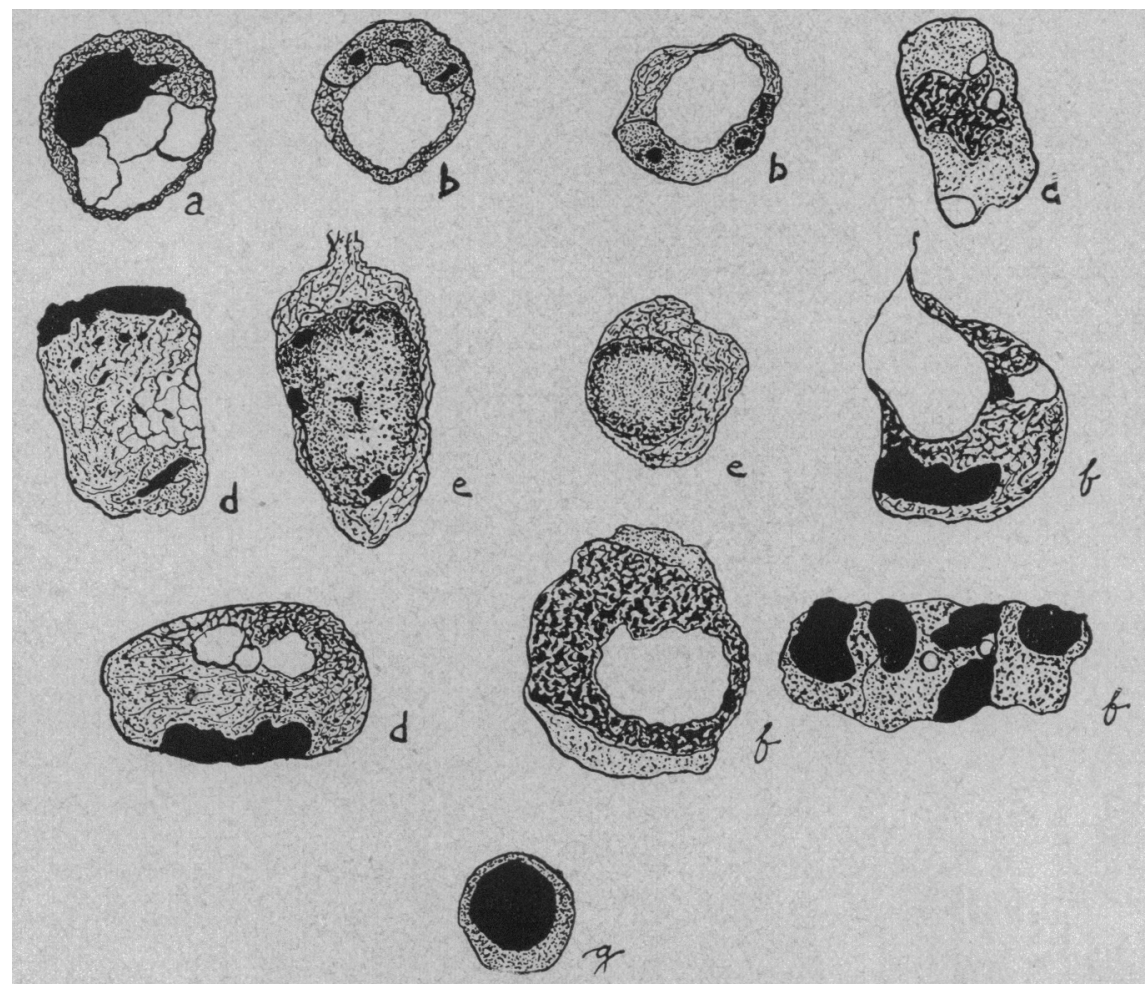

Fig. 5.-Types of cells seen in malignant tumors of the motochord (drawn to same scale). (a) Cells with heavily stained, irregular nucleus only slightly eccentric and with relatively more protoplasm bearing several large sized vacuoles. (b) Cells with thin rim of finely granular protoplasm, a single large central vacuole which has often ruptured the enclosing protoplasm, and a marginal nucleus which varies in size, staining properties and is often multiple. (c) Cuboidal or columnar cells with central irregular nucleus and protoplasm with a few small vacuoles. (d) Large cuboidal, columnar or polyhedral cells with a narrow marginal irregular heavily stained nucleus and relatively large amount of protoplasm containing a few small vacuoles. (e) Slightly irregular, cuboidal polyhedral, or rounded cells bearing a relatively large granular nucleus and without vacuoles in the protoplasm. (f) Irregular and compound cells with peculiar arrangements of the nucleus and protoplasm, formed, probably, by fusion of cells after partial discharge of mucein or by cell division under pressure. (g) Small 1ymphocyte for comparison. 
in the more areolar portions of the tissue. Deep in the tissues, near the muscles, there was a notable lymphocytic reaction with quite dense fibrosis of the structures. In these deeper layers the chordoma cells showing multilobulated nuclei, sometimes central, generally eccentric and occasionally scaphoid, and always situated in a relatively large amount of pale blue protoplasm, were in small groups numbering from three to eight cells per group.

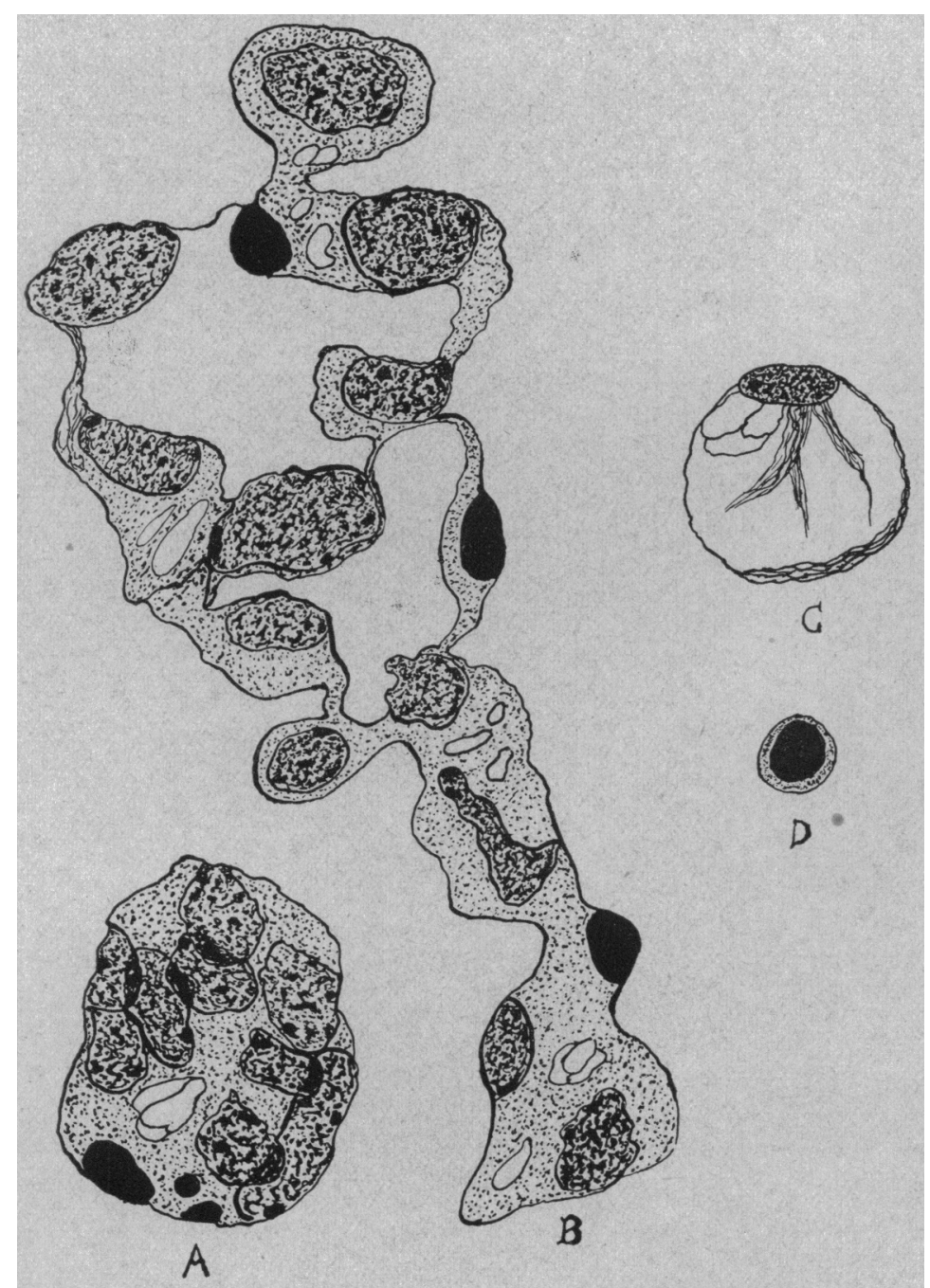

Fig. 6.-A, nests of chordoma cells as seen in mesenteries and tunica vaginalis of the testicles; B, type of cell arrangement seen in all four cases of chordoma-fusion of cell walls, discharge of mucein, and formation of vacuolated syncytial like structure; C, type of benign chordoma cell; D, small lymphocyte for comparison.

The blood vessels of this area were thickened but nowhere were foreign cells seen penetrating the walls, but doubtless many of the smaller arterioles were obliterated by extensions of cells. One large subcutaneous artery was surrounded by chordoma cells, but the walls proper were not affected. The 
accompanying nerves with their sheaths were also surrounded but not infiltrated, however, in some sections of the compound fasciculae, a few chordoma cells were seen between the nerve bundles in the epincurium.

The small regional lymph glands showed a dense obliterative central fibrosis and an irregularly thickened capsule from which extensions radiated into the glandular tissue greatly reducing the lymphoid elements. The surrounding tissues were filled with malignant chordoma cells but none had entered the lymph glands.

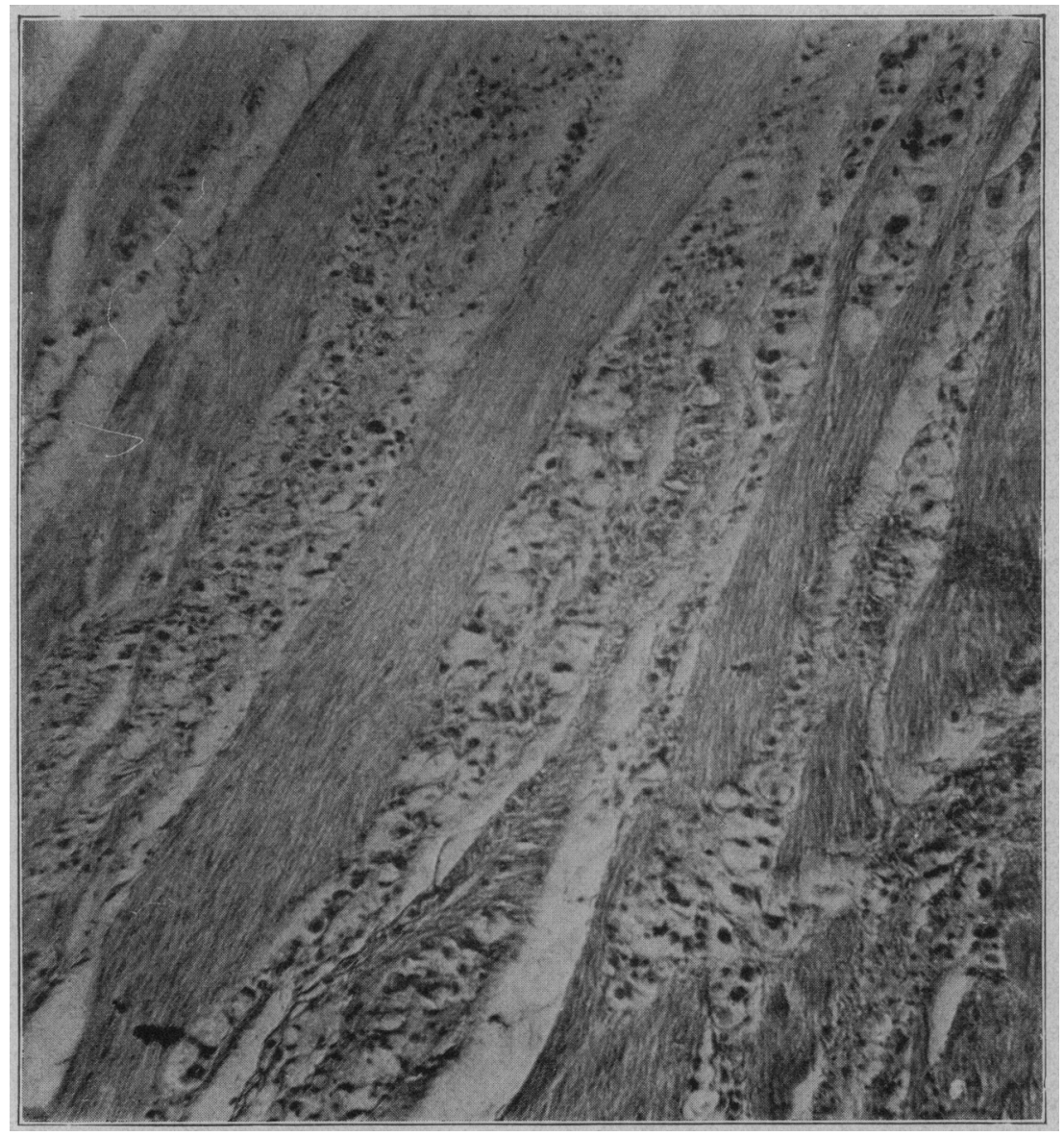

Fig. 7. - Photomicrograph of section of rectal wall in Case 1, showing large vacuolated cells with eccentric nuclei separating bundles of muscle and connective tissue.

Sections of Mesenteries. - There was a fibrous tissue increase in wide bands throughout, with many large areas of fat cells in which were seen accumulations of rapidly dividing chordoma cells arranged in nests (not unlike carcinomatous formations) often containing as many as twenty-five or thirty cells (Fig. 6 A).

The lymph gland capsules were enormously thickened, fusing with the surrounding structures, and were infiltrated with actively growing tumor cells, but the glands themselves, although they exhibited considerable increase in stroma 
were not infiltrated by these cells, all extensions of which appeared to stop at the inner capsular margin.

Walls of Rectum.-The walls of the rectum showed a dense infiltration of all coats with chordoma cells of both the lower embryonic type, and of the older vacuolated eccentric nucleated variety which extended along the fascias between the muscle bundles (Fig. 7) and into the submucosa. The mucosa was not remarkable with the exception of occasional small sized necroses probably produced by pressure changes.

Prostate. - The prostate gland presented a universal adenoplasia of first degree, with irregularity of the acini and hyperplasia of cells, and with considerable concretion deposits in the centers of the follicles. There were no tumor cell extensions in the vicinities of the prostatic glands, with the exception of an occasional small patch of widely separated cells usually situated near one of the acini, but in the fascias surrounding the prostate and between it and the bladder walls and rectal walls there were both nested groups and diffuse infiltrations of chordoma elements of the darkly stained, large nucleated types in a matrix having a high mucein content.

Testicles.-The testicular acini were characterized by a thickened basement membrane, with the attached spermatogenic cells greatly reduced in number and with no spermatozoa. The interstitial tissues were sclerotic throughout. The tunica vaginalis and tunica albuginea were fused and enormously thickened. The tumor infiltration in these regions was patchy in distribution, and in places nests of small dark nucleated chordoma cells, surrounded by clear spaces, gave the general appearance of carcinomatous arrangement; however, the peculiar pale staining mucinous matrix was differential. Neither the acini nor the interstices of the glands proper had been attacked, but the process was limited to the envelopes of the organ, and extended along the spermatic cord, following the fascias, and widely separating its structures, principally from the associated tremendous fibrous tissue production.

Sections of Kidney.-(Description common to both kidneys.) The capsule of the organ was greatly thickened, being a dense, almost solid mass of chordoma cells which filled the entire capsule and were lying close to the glandular margin, but had not dipped down between the cortical structures excepting where the capsule had been followed. The tumor cells of this region were in a connective tissue stroma and representatives of all cell types of Figure 5 were noted.

The outer zones of the kidney cortex were densely sclerotic and in patches only the knotty remains of tubules and glomeruli were scen. Many convoluted tubules were hyperplastic with a slight granular exudate in the centers. Deeper in the cortical structures, the glomeruli were somewhat swollen and hemorrhagic, and the tubules were distorted, the cells which were originally flattened exhibiting advanced albuminous degeneration. In a few areas dense intratubular and extratubular hemorrhages were noted, and the stroma, in general, was increased throughout the organ.

Suprarenals.-The tissues surrounding the glands had fused with those of the kidney, and contained many thickened vessels and wide zones of fibrosis with a large amount of fat and areolar tissue.

Scattered discretely through these tissues, and particularly in the areolar areas were both isolated and small accumulated groups of tumor cells, without infiltration of the suprarenal cortex. The cortex of the gland showed considerable atrophy with a few localized compensatory glandular hypertrophies. The zona glomerulosa remained only in a few marginal knots, and the lower zones appeared to be degenerated and exhausted. The medullary portion was heavily sclerotic, narrowed and presented much lymphatic infiltration.

Liver.-The capsule was thin but fibrous, and showed no evidence of infiltrating tumor cells. There were no tumor cells through the sections taken from the organ, but the substance exhibited diffusely scattered blood pigment and an irregularly distributed fatty degeneration extending through the lobules and about the central lobular veins. 
There was a numerical reduction in the liver cells, and the remaining ones were swollen, pale and often vacuolated. A moderate increase in connective tissues was noted in the portal canals.

Pancreas.-Through most of the organ there was a dense sclerosis with complete atrophy of about half the acini, the remaining ones being bunched in small groups and presented heavily stained cells. The islands were distorted and sclerotic showing a reduction in the number of cells. In the fascias about the gland many irregular groups of chordoma cells, held together by a mucinous stroma, were surrounded by fibroblastic productions. These tumor cells had followed the interlobular stroma for short distances into the gland, but in no instance were the tubules involved, excepting perhaps by pressure.

Spleen.-The capsule was thickened, sending ramifications of large size into the substance of the organ, and contained considerable dark brown pigment,

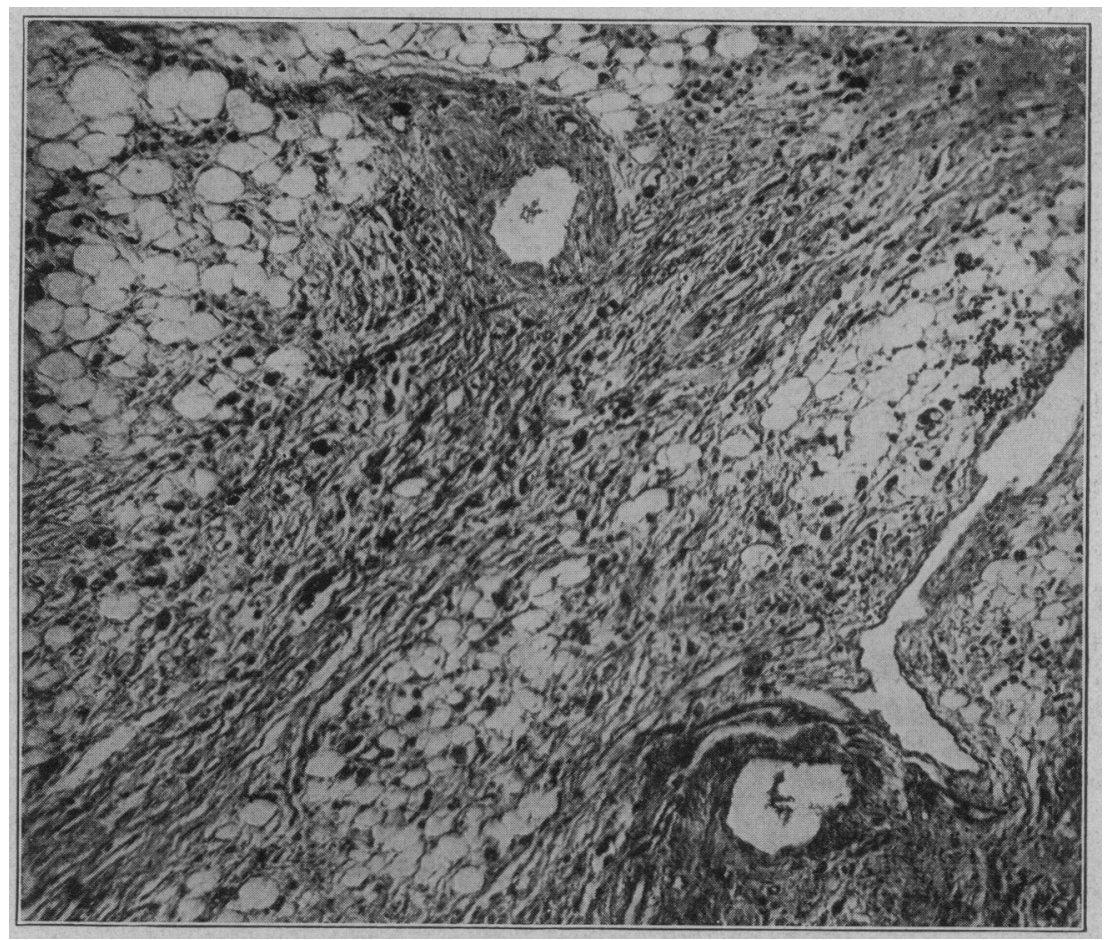

Fig. 8.-Photomicrograph of chordoma cells scattered among the connective tissues and fat cells of the mesenteries (Case 1).

but there were no chordoma cells in the sections studied. There was a general increase in splenic stroma, particularly about the vessels, the malpighian bodies were small and the arterioles were thickened and occasionally hyaline.

Lungs.-No tumor metastases were seen in the lungs, which were not remarkable, with the exception of some congestion of the alveolar arterioles and a peribronchial round cell infiltration.

Thyroid.-The interfollicular structures were filled with epithelial and lymphoid cells and the colloid was diminished to about one-half the usual amount. Wide bands of connective tissue excessively lobulated the organ.

Heart.-The muscle fibers showed some separation and replacement, the muscle cells were pale and atrophied, bearing pale granular nuclei, at the poles 
of which was a large amount of brown pigment. An occasional large endothelial cell was noticed between the muscle fibers.

Cercbral Cortex.-There were no unusual changes, with the exception of mildly edematous perivascular lymph spaces and some thickening of the overlying meninges.

Cerebellum.-The meninges covering the leaflets and extending into the fissures showed fibrosis and some endothelial hypertrophies. The architecture of the cerebellar layers was not remarkable, but there was some reduction in the number of purkinjean cells, with a neuroglial felting of the areas.

Spinal Cord.-The cord presented no striking changes, but there was some overlying chronic meningitis and an unusually large number of modified ependymal elements in the central canal region.

Section Including Pclvic Sympathetic Ganglia.-Large patches of chordoma cells were present in sections in which the associated connective tissue response was much less in evidence.

The sympathetic ganglia were surrounded by, but not infiltrated with, tumor cells. Many of the ganglion cells were shrunken, heavily pigmented and surrounded by large pericellular spaces. Some of these cells were acidophilic in reaction, and a few were completely disintegrated.

Pituitary.-The posterior lobe showed dense sclerosis and considerable brown pigmentation, while the anterior lobe was only moderately sclerotic, and the acini were large, well stained and in a good state of preservation.

CASE 2 (U. S. Naval Hospital).-A male, white, aged 30, with negative family, past and venereal histories, was admitted to the hospital June 2, 1919, with a history of persistent constipation, with no passages of feces for five days. Vomiting started twenty-four hours after admission, and because of increasing abdominal symptoms a laparotomy was done June 4. All intestines were found to be dilated with fluid, and an annular mass about one inch in length, and of the thickness of a thumb was found obstructing the sigmoid. This mass, with the sigmoid, was fixed to a "stab wound" of the left side and resected four days later (artificial anus). The tumor was diagnosed as carcinoma.

A second laparotomy was done Oct. 20, 1919, which showed the large intestine and peritoneum to be covered with small nodules, which were clinically considered to be either carcinoma or tuberculosis. The pathologic diagnosis from sections of the peritoneal nodules was sarcoma.

Nov. 4, 1919, an operation was done for rectal fistula, which had formed, with resection of the lower rectum, and another laparotomy again showed many nodules over the omentum, but the tumors seemed smaller and less numerous than at the previous operation.

Death occurred Feb. 25, 1920, with clinical evidence of intestinal obstruction. There was a very slight emaciation of the body and tumor masses were palpable through the abdominal wall.

\section{NECROPSY}

A necropsy was performed, and the parietal peritoneum, the omentum, the mesenteries and the intestinal walls were studded with small nodules like those seen at the operations. The intestinal obstruction had been caused by a large mass of tumor about 6 inches through, involving the omentum, descending colon and sigmoid. Several associated smaller masses were noted, with enlargement of the retroperitoneal and mesenteric lymph glands.

The liver was congested and exhibited small nodules of tumor tissue in the capsule but none in the substance, and there were no metastases into the thorax.

Microscopic Findings.-Sections taken from the wall of the resected rectum showed the muscle bundles to be separated by round and cuboidal, rapidly multiplying cells; having clear vacuolated protoplasms, and deeply stained, irregular eccentric and often multiple nuclei, surrounded by an abundance of chronic inflammatory tissue. Sections including the mucosa presented no 
remarkable changes in this structure nor in the immediate submucous tissues, but the tumor infiltration was rather limited to the muscular layers No malignant changes were noted in the mucosa or skin of the mucocutaneous junction at the anal opening.

Sections of the intestinal walls taken at the necropsy gave the impression of a more rapid growth of the tumor than those taken previously at operation. The streaks of malignant cells had split the muscle fibers into narrow fine strands of tissue, which were atrophied, forming a stroma in places around the individual cells or small groups of cells, although, in general, there was very little tendency to the type of grouping seen in Figure 6 (A and B). A large majority of the cells were closely packed and of the large vacuolated variety with eccentric nuclei (Type 1 of classification), with less surrounding connective tissue reaction than in the earlier sections, and apparently rapidly extending (Fig. 9). None of the larger vessels were penetrated by the growth.

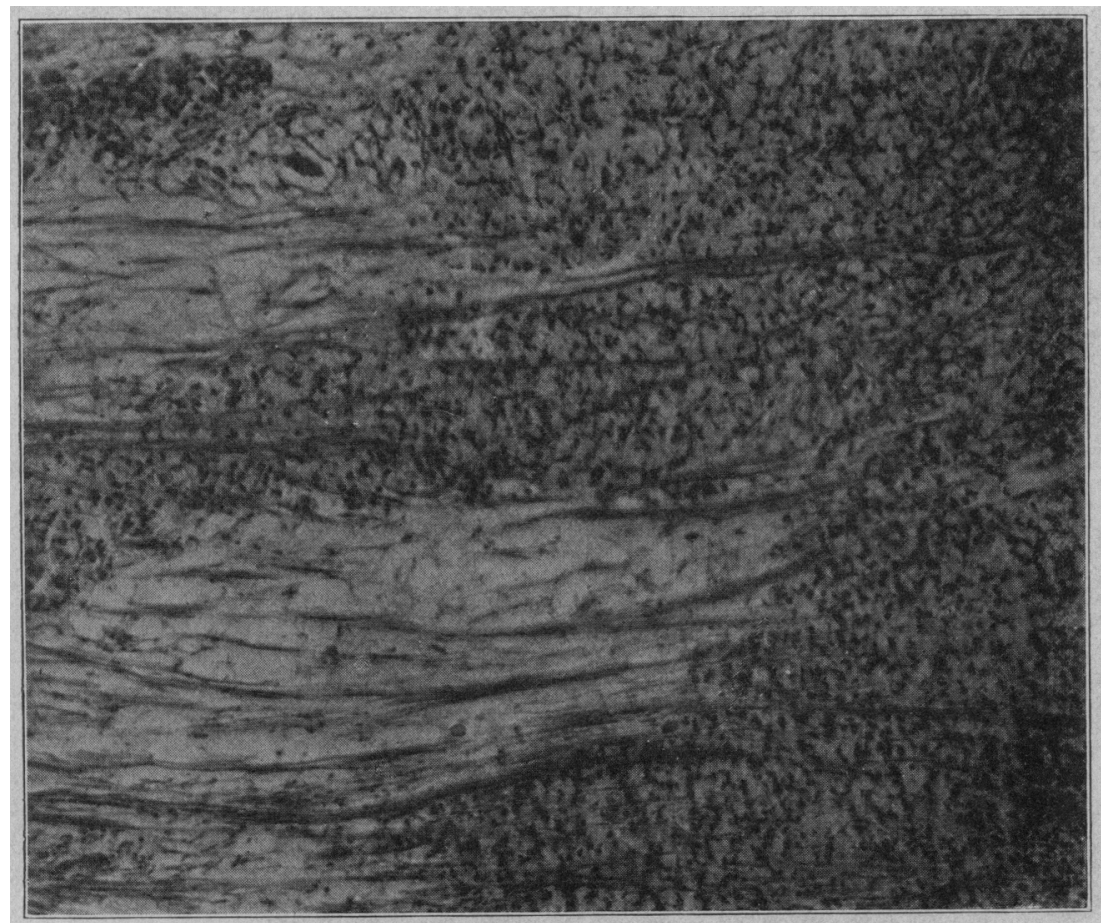

Fig. 9.-Photomicrograph of section of intestinal wall from Case 2 demonstrating rapid infiltration of chordoma cells in the muscular layers.

All the tissues examined from this case were of the above type of reaction, and no evidence of carcinomatous changes or tuberculous lesions was discovered.

CASE 3 (Case of Dr. Riggs, South Dakota).-White, male, aged 58, merchant with a negative family history, and a personal history which was negative until two years before operation, at which time he complained of frequent urination with burning. Cystoscopic examinations were negative and the condition was relieved by passing urethral sounds.

The patient entered a hospital in May, 1920, complaining of pains in the rectal region, the right leg. and also in the arms, and he felt chilly. He remembered that during the past two years he had had some discomfort about 
the rectal region, occurring usually in the night, and relieved by changing the position. His condition was diagnosed as ischiorectal abscess.

Physical Examination.-This revealed a normal chest, abdomen and prostate. The tonsils were small and "positive." Blood pressure, 88-92/60.

Dorsally, at the lower portion of the coccyx was a mass about the size of a prostate, composed of two distinct nodules, slightly movable, apparently not attached to the rectum, and of the consistence of fibrolipoma.

Treatment.-The tonsils were removed. The blood pressure became better (110), and the tumor was excised.

Tumor.-The growth measured 6 by $5 \mathrm{~cm}$. in two diameters, was enclosed in a definite but thin capsule (Fig. 10), and contained one piece of bone suggesting the tip of the coccyx. The tissue seemed very cellular, with a fine stroma, and was dark brown in color, with gray and white areas. The substance was friable, and some small granular, elevated masses were easily picked from the tissue. The structure did not suggest chordoma or cancer in a dermoid, but was not unlike a giant cell tumor belonging to the type of malignant sarcoma.

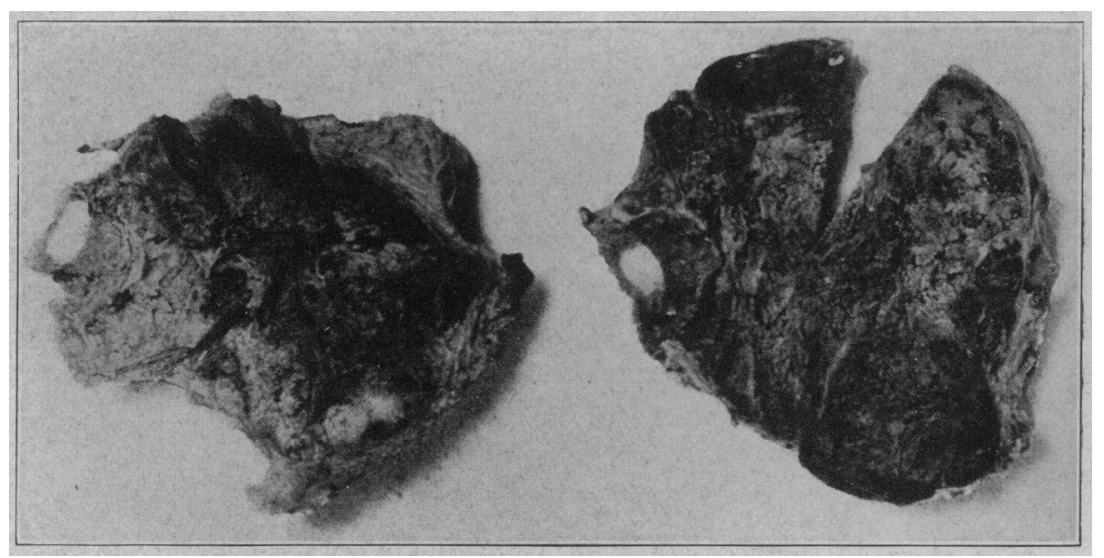

Fig. 10.-Gross sections of the chordoma removed from the rectal region in Case 3.

Microscopic Examination.-This revealed a very cellular structure, with a tendency to alveolus formations, with separations by wide dense strands of eosin staining, hemorrhagic, fibroblastic tissue, which in places included small groups of cells. The cells rested on this and grew out in capillary masses, with fusion of cytoplasm and exudation of mucein, but with no definite intercellular substances. The cells in the center were undergoing disintegration leaving mucein and an eosin staining débris.

The predominating types of cells were cuboidal and round with a lightly staining protoplasm, while the nuclei were large, granular, centrally situated (Fig. $5 \mathrm{E}$ ), and showing many forms of karyokinetic figures. There were a few areas showing vacuolated cells bearing the half moon eccentric nuclei typical of chordoma; there were also a few multinucleated cells of giant cell dimensions.

CASE 4 (Sent in by Dr. Bassett, Savannah, Ga.).-In September, 1914, a white female, aged 22, applied for relief on account of constant pain in the rectal region. Othewise she was in good condition, showing no loss of weight. Two years before a surgeon had excised a portion of a rectal tumor, which he diagnosed as cancer.

Rectal Examination.-A small hard nodular, irregular mass about 2 inches long was situated at the left side of the rectum and attached to the pelvic fascia, but was not attached to the wall or mucous membrane. 
The rectum was incised and a specimen removed. The condition at this time was thought to be quite independent of any previous operation. The possibilities of carcinoma, endothelioma and tuberculosis were considered. The specimen removed for examination was a small piece of firm, white tissue resembling a gland, and at the time was thought to be probably of epithelial origin.

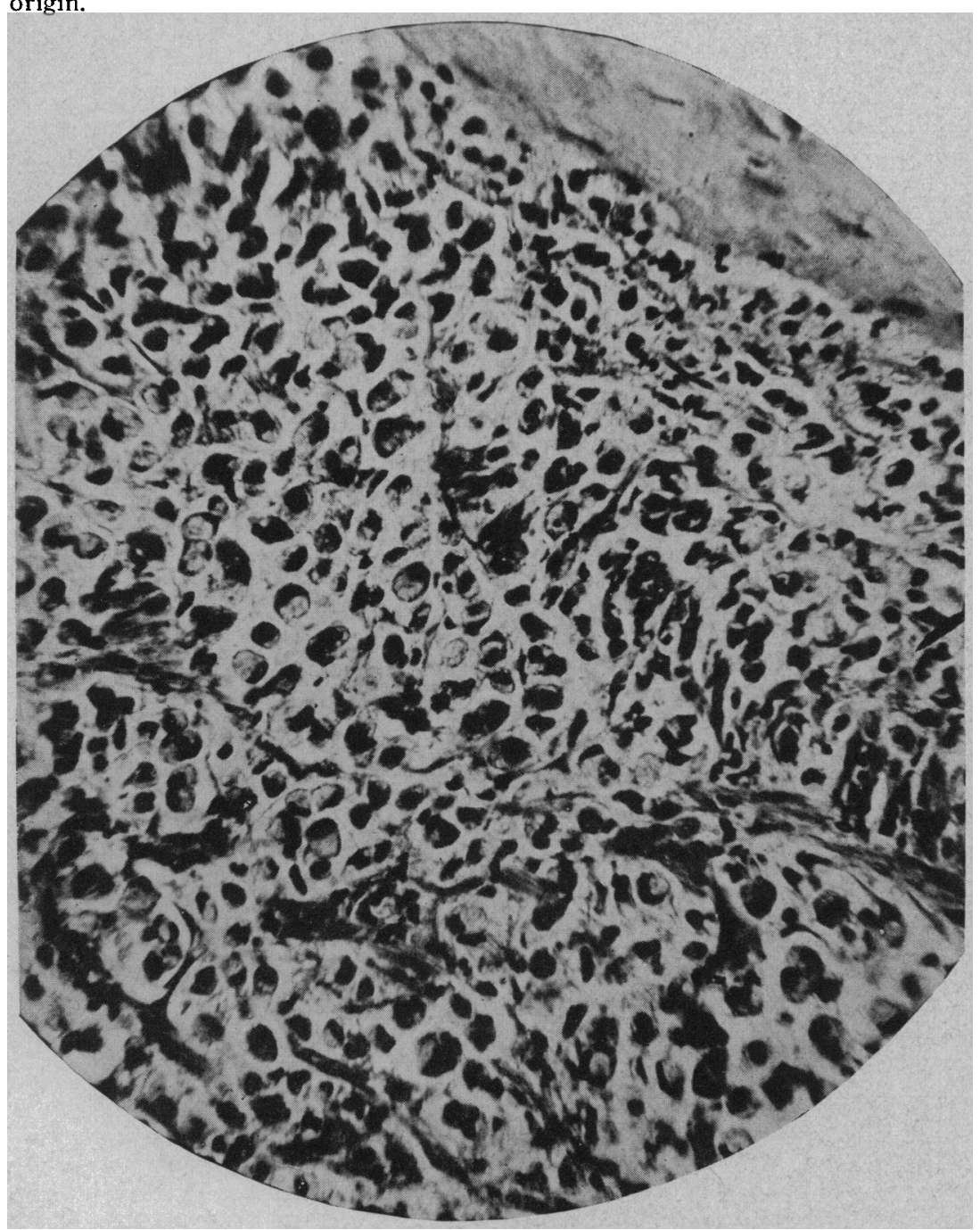

Fig. 11.- Photomicrograph of section taken from tumor metastasis in cervical region in Case 4 , illustrating the varieties of cells characteristic of malignant chordoma.

About a year later (October, 1915) the tumor recurred at the rectum with complete obstruction, necessitating opening of the sigmoid above (artificial anus). The patient was now considerably emaciated, and a lump the size of an apple (probably metastasis) had grown in the neck. 
Microscopic Examination.-The specimen removed from the rectal region showed a few irregular masses of dense bone, in the meshes of which malignant vacuolated cells of polyhedral and round outlines, with eccentric nuclei, were distributed. These cells resembled those seen in the other three cases, but, on the whole, were somewhat smaller, and showed a pronounced tendency to small groupings in dense connective tissue. The stroma of this tumor was abundant, and many areas of areolar tissue were filled with ringlike cells.

The blood vessels were all thickened, but not, as a rule, penetrated, although in one instance chordoma cells were noted growing in the walls and in the central portion of a thrombosed artery.

At death there were several other masses in the cervical lymph glands, the size of large walnuts. A necropsy could not be obtained, but a tumor was taken from the neck for diagnosis.

The microscopic characteristics were like those of the original tumor from the rectal area, with the exception of being more cellular and with less connective tissue production, and sections exhibited the various types of cells described above for the other tumors and are well illustrated in Figure 11, a photomicrograph from the tissues of this case.

\section{CONCLUSIONS}

1. In the majority of cases of chordoma reported the tumor occurred in the spheno-occipital region, so that it is rather singular, but fortunate, to have four instances of this type of malignancy growing from the sacrococcygeal site, giving an opportunity for comparative studies.

2. There is no history suggesting the etiology in Cases 2, 3 and 4, but in Case 1 there is a strong probability of injury to the coccygeal area, and as this region is the site of frequent trauma, the possibility of injury as a causative factor must be considered. (A definite history of traumatism was obtained in the case reported by Albert.)

3. Compartive Summary: In Case 1 the symptoms (diarrhea, nausea, abdominal tenderness and headache) became severe enough to attract attention only four months before death, during which time - maciation and cachexia developed rapidly. This patient was an insane man, in whom subjective symptoms may have been and probably were present long before his condition was complained of or came to the attention of the physician.

A complete necropsy was performed which revealed the principal tumor broadly attached to the sacrum and coccyx, from which site extensive invasions, associated with tremendous connective tissue productions, had radiated through the fascias, capsules and walls of the abdominal organs without infiltrating glandular structures or affecting mucous membranes, except by pressure. The inhibiting effects of this diffuse growth on the functions of the abdominal viscera must have been considerable. There were no true metastases nor nodular formations in the path of the tumor.

In Case 2 death occurred about eight months after the onset of acute symptoms (persistent constipation, vomiting, increasing abdominal symptoms). Early laparotomy showed obstruction of the sigmoid, 
and a later laparotomy revealed many small nodules in the peritoneum and in the large intestine. A rectal fistula formed, which was corrected, and a third laparotomy showed many nodules over the omentum.

In this case the emaciation of the body was slight. A necropsy was performed. No mention was made of a tumor attached to the sacrum, but a large mass was described involving the omentum, sigmoid and descending colon, as well as a general distribution of many small nodules in the peritoneum, mesentery and intestinal walls. This feature of growth was quite different from that observed in Case 1.

The earlier sections from Case 2, taken from the resected rectal wall, exhibit a liberal connective tissue response with relatively few chordoma cells, while those taken from the intestinal walls at necropsy were rich in tumor cells and with less connective tissue-showing, in general, a more rapid growth, as in Case 1 no metastases were seen in the thorax.

One patient (Case 3) gave a history of rectal discomfort for two years before the acute symptoms (chilliness, rectal pain, pains in legs and arms) began. A slightly movable, irregular, mass was palpated at the lower portion of the coccyx. This mass measuring $6 \times 5 \mathrm{~cm}$. was excised and found to correspond microscopically with the characteristics described for chordoma. The operation was performed about a year ago. The present condition of the patient is not known to me.

The last patient (Case 4) sought relief from acute symptoms (constant pain in rectal region) a little more than a year before death. At the time of the acute onset she was apparently in good general physical condition, but rectal examination revealed a small, firm, nodular tumor outside the rectal wall in the pelvic fascia. A year later, the tumor in this area produced complete obstruction of the rectum necessitating sigmoid resection (artificial anus). The patient then showed emaciation, and metastases were forming in the cervical region. Death followed, but no necropsy was performed, although a nodule was taken from the neck for diagnosis.

The cells and general structure of the metastasis were those of the original rectal tumor.

It is regretted that a necropsy could not be obtained in this case, as apparently there was a true metastasis to the neck, and it would have been instructive to observe the mode of extension, if any, through the abdominal viscera.

4. So few of these tumors have been recognized and reported that one hesitates to offer an opinion as to their frequency, but that they are of far more clinical importance than has heretofore been considered is quite evident, and judging from the variety of diagnosis made in the four cases cited by as many competent pathologists and surgeons, these tumors are much more frequent than was formerly 
supposed, and they have undoubtedly occasionally been classified among the other forms of malignancy.

A differentiation of chordoma from myxochondroma and from colloid carcinoma of the rectal region is not readily accomplished, as the types of cells are often similar, and many other features, such as mucein content, cell formations and stroma arrangements are seen in common. The absence of actual cartilaginous formations speaks against myxochondroma, and broad attachments to the sacrum, with extensive infiltrations through the supporting tissues, and at the same time exhibiting a tendency of limitation to the capsules of organs and glands, avoiding actual glandular structures, and the infrequency of metastasis, are features pointing toward chordoma rather than colloid cancer.

5. Malignant chordoma may be considered as causing 100 per cent. mortality. Because of the extensive infiltration of the regional fascias, and the difficulty of early diagnosis, operative treatment probably rarely effects a cure, but, of course, excisions of the principal tumor mass, and intestinal resections have been beneficial in the removal of pressure and pain phenomena. ${ }^{9}$

9. The following references also bear on this subject:

Ewing: Neoplastic Disease, 1919, p. 188.

Mallory: Principles of Pathologic Histology, 1914, p. 400.

MacCallum: Textbook of Pathology, 1918, p. 1022.

Adami: Principles of Pathology 1:761, 1910. 